\title{
Las sesiones de trabajo como técnica de Relaciones Públicas. Un estudio de caso
}

\author{
Recibido: 05 de diciembre de 2013 \\ Aceptado: 01 de agosto de 2014 \\ Publicado: 28 de noviembre de 2014
}

\author{
Cindy Huaripata Yizuka \\ cindyhuaripata@gmail.com \\ Universidad de San Martín de Porres (Perú)
}

\begin{abstract}
Resumen: El objetivo general de la presente investigación fue determinar la influencia de la organización de las sesiones de trabajo como técnica de Relaciones Públicas en la imagen que tienen los clientes de una empresa. Esta técnica permite a las organizaciones acercarse a sus públicos a fin de comunicar sobre sus productos, servicios, actividades y conducta. En este sentido, se espera generar posicionamiento, identificación y fortalecer los vínculos de relación y comunicación con el público. Precisamente, este estudio de enfoque cuantitativo y explicativo realizado en dos grupos (experimental y control), demostró que la organización de las sesiones de trabajo influye en la imagen que tienen los clientes de una empresa. Sobre la base de los resultados hallados, se afirma que existe un nivel de correlación del $96.7 \%$ entre ambas variables.
\end{abstract}

Palabras clave: Sesiones de trabajo, organización, técnica, Relaciones Públicas, eventos, comunicación, imagen, clientes, satisfacción, relación.

\begin{abstract}
The main objective of this research was to determine the influence of the organization of work sessions as a technique of PR on the clients'image of a company. This technique enables organizations to approach their target public in order to communicate about theirs products, services, activities and behavior. It is expected to obtain placement, identification and also, to strengthen relation and communication with the public. Precisely, this explanatory research carried out in two groups (control and experimental) demonstrated that the organization of the work sessions in deed has influence on the image of the clients of a company. According to the results, it is stated that there is a $96.7 \%$ level of correlation between both variables.
\end{abstract}

Key words: Work Sessions, Organization, Technique, Public Relations, Events, Communication, Image, Clients, Satisfaction, Relation. 


\section{Introducción}

Basándonos en Huaripata (2013), este artículo resume la importancia de organizar las sesiones de trabajo como técnica de Relaciones Públicas y cómo este tipo de eventos influye en la imagen que tienen los clientes de una empresa, es decir, en aquellos que han asistido al certamen, comprobando la relevancia de su aplicación para lograr una buena imagen en los públicos.

Las Relaciones Públicas tienen como campo de estudio a la organización y como protagonista al hombre en su acción relacional y comunicacional, razón por la cual las empresas deben generar, reforzar y mantener vínculos con sus públicos. Es así que, a través de las Relaciones Públicas, es posible comunicar adecuadamente, modificar actitudes e influir positivamente sobre cada uno de sus públicos, quienes se forman una imagen de la organización. Entonces, ¿cómo hacerlo?, ¿cómo lograrlo? Haciendo uso de las técnicas de Relaciones Públicas, que son un conjunto de procedimientos basados en las ciencias humanas y sociales. Estos procedimientos son unitarios y diferentes según la situación, acción y objetivos de cada organización.

Actualmente existen diversas técnicas de Relaciones Públicas empleadas por las organizaciones para comunicarse con sus públicos y lograr el cumplimiento de sus objetivos. Sin embargo, estas técnicas deben ser puestas en marcha por un profesional de las Relaciones Públicas, quien (basado en el conocimiento aprendido y en la práctica adquirida) cumplirá sus labores con eficiencia y calidad, a diferencia de cualquier otro que no sea de la profesión.

Para este estudio se eligió a las sesiones de trabajo como técnica de Relaciones Públicas, cuyo propósito es reunirse con los clientes de la organización para invitarles un ágape. Es preciso mencionar que dicho alimento es el motivo para concretar la reunión, pero la esencia en sí es el desarrollo de una actividad técnica o intelectual. La organización de sesiones de trabajo como técnica de Relaciones Públicas es un evento que requiere una preparación, ejecución, seguimiento y evaluación. Debe ser llevado a cabo por un relacionista público profesional, quien debe formar y presidir un comité organizador, de lo contrario no responderá a los objetivos deseados.

Las empresas deben organizar las sesiones de trabajo de manera planificada, no solo como muestra de respeto y consideración a los públicos, sino porque es una buena oportunidad para fortalecer la relación y comunicación (directa y efectiva) con sus clientes. De esta manera, ellos evalúan si la sesión de trabajo cumplió con sus expectativas analizando los elementos que intervinieron en ella según la experiencia y relación que han tenido con la organización antes de asistir al evento. No obstante, luego de su participación, esta percepción puede mantenerse, reforzarse o verse disminuida, situación distinta para quienes no han participado en dicho evento. Es importante mencionar que la sesión de trabajo (como técnica de Relaciones Públicas) solo representa uno de los tantos aspectos que influyen en la imagen total de la organización, porque también existen otros factores que los clientes valoran de la organización, tales como sus productos, servicios, actividades y conducta. Cada uno forma parte de la imagen parcial de la organización. 
La imagen hace referencia a la actitud que tienen los clientes sobre la organización. Si bien es cierto, no todos los clientes mantienen la misma relación con la empresa. A algunos solo les pueden interesar los productos y servicios que ofrece. Tal vez otros prefieran participar únicamente en sus actividades y también puede darse el caso de que unos tan solo evalúen la conducta de la empresa. Dicho así, cualquiera de estos escenarios contribuye a consolidar la imagen de la empresa y la suma de todos estos elementos forman la imagen total, que puede ser positiva o negativa. Precisamente, las empresas deben conseguir la satisfacción en general de sus clientes, que es la conformidad expresada y demostrada por parte de ellos. Para lograrlo, es importante que exista en la organización una coherencia entre lo que dice y lo que hace. En caso contrario, los resultados no serán positivos, ocasionando el distanciamiento y hasta la pérdida de clientes. Finalmente, las empresas que decidan aplicar las sesiones de trabajo como técnica de Relaciones Públicas podrán evaluar, en un plazo determinado, la imagen que tienen los clientes y su repercusión en la imagen general de la empresa a través de distintos indicadores de medición.

\section{Objetivo de la investigación}

\subsection{Objetivo general}

Determinar la influencia de la organización de las sesiones de trabajo como técnica de Relaciones Públicas en la imagen que tienen los clientes de una empresa.

\subsection{Objetivos específicos}

- Determinar la influencia de las sesiones de trabajo (como técnica de Relaciones Públicas) en el elemento componente cognitivo, emocional y conductual de la imagen-actitud que tienen los clientes de una empresa, así como en la satisfacción general que estos pueden experimentar ante una organización.

- Determinar el grado de influencia de la evaluación de las sesiones de trabajo (como técnica de Relaciones Públicas) en el elemento componente cognitivo, emocional y conductual de la imagen-actitud que tienen los clientes de una empresa, así como en la satisfacción general que estos pueden experimentar ante una organización.

\section{Metodología}

Se adoptó un enfoque cuantitativo por ser secuencial y probatoria, con un alcance de investigación explicativo a fin de determinar si la organización de sesiones de trabajo influye en la imagen que tienen los clientes de una empresa. En ese sentido, el diseño 
de investigación utilizado es cuasi experimental o diseño comprometido ${ }^{1}(c f$. Hernández, Fernández y Baptista, 2010: 148), en el que se manipula por lo menos a una variable independiente a fin de observar y evaluar su efecto y relación con una o más variables dependientes.

Es así que se llevó a cabo la investigación con dos grupos: experimental y control, cada uno conformado por 200 clientes. El primero fue el grupo experimental, es decir aquellos clientes que fueron invitados a las sesiones de trabajo. Inicialmente se les invitó a responder una encuesta sobre la imagen de una empresa. Dicha encuesta se hizo por entrevista (personalmente y/o telefónicamente), quince días antes de realizada la sesión de trabajo. Posteriormente, a los mismos clientes (primer grupo) se les autoadministró una segunda encuesta el día que se llevó a cabo el evento (minutos antes de que finalice) sobre las sesiones de trabajo como técnica de Relaciones Públicas y una tercera encuesta sobre la imagen de una empresa (la misma que se aplicó quince días antes de que se llevara a cabo la sesión de trabajo).

Sin embargo, fue necesario contar con un grupo control (segundo grupo) para determinar si efectivamente los resultados obtenidos con el primer grupo eran válidos y si se cumplían los objetivos de la investigación. En ese sentido, al grupo control, conformado por 200 clientes, que no fueron invitados a la sesión de trabajo, se les autoadministró la encuesta de imagen de una empresa por entrevista (personalmente y/o telefónicamente).

Es importante mencionar que gracias al segundo grupo denominado control, se pudo determinar si la imagen de la empresa cambió (de manera positiva o negativa) o se mantuvo igual sin la intervención de la sesión de trabajo como técnica de Relaciones Públicas.

\subsection{Tipo de investigación}

Estudio de caso. Investigación de enfoque cuantitativo y explicativo.

\subsection{Diseño y procedimiento}

Investigación cuasi experimental de cohorte transversal, debido a que la variable independiente no ha sido controlada y el estudio se ha dado en un determinado tiempo. Dicha investigación pretende demostrar que la organización de sesiones de trabajo (variable independiente) influye en la imagen que tienen los clientes de una empresa (variable dependiente).

Con la finalidad de tener el control de que otras variables extrañas no alteren a la variable dependiente para establecer que es la variable independiente la que tiene influencia en ella, se eligió un grupo control con las mismas características al grupo experimental. Este diseño

1. Es aquel diseño en el que no se puede controlar al 100\% todas las variables extrañas e intervinientes. 
cumple con el requisito ${ }^{2}$ de la validez interna o control. La investigación corresponde al tipo de diseño de grupo de control no equivalente, con asignación no aleatoria (figura 1):

Figura 1: Esquema del diseño de grupo de control no equivalente ${ }^{3}$.

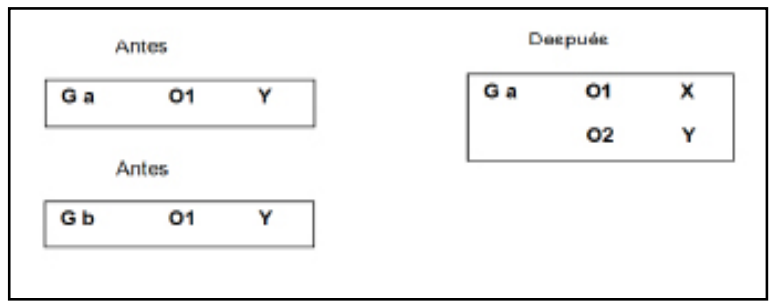

Fuente: Elaboración propia.

\subsection{Población}

Representada por 1003 clientes de una empresa privada del rubro de tecnologías de la información en Lima Metropolitana 2011-2012.

La población conformada por unidades con características similares, sin embargo es importante saber identificarlas en base a sus atributos propios para posteriormente clasificarlas en perfiles.

\subsection{Muestra. Unidades de análisis}

El tamaño ${ }^{4}$ de la muestra ${ }^{5}$ es de 400 clientes de una empresa privada del rubro de tecnologías de la información en Lima Metropolitana 2011-2012.

\subsubsection{Técnica de selección de muestras}

La técnica de selección de muestra utilizada en esta investigación es el muestreo no probabilístico intencional. En ese sentido, 400 clientes $^{6}$ en representación de sus respectivas

2 Los tres requisitos de un experimento son: manipulación intencional de una o más variables independientes, medir el efecto que la variable independiente tiene en la variable dependiente y el control o la validez interna de la situación experimental (Hernández, Fernández y Baptista, 2010).

3 Donde $\mathrm{X}=$ variable independiente; $\mathrm{Y}=$ variable dependiente; $\mathrm{O} 1$ = medición previa (antes del evento) de la variable dependiente; $\mathrm{O} 2$ = medición posterior (después del evento) de la variable dependiente; Ga $=$ grupo experimental que participa en las sesiones de trabajo; y $\mathrm{Gb}$ = grupo control que no participan en el evento y se les aplica la encuesta referente a la variable dependiente.

4 Este resultado se obtuvo a través del programa estadístico STATS.

5 La investigación contó con criterios de exclusión e inclusión de una muestra.

6 El perfil seleccionado: gerente general. 
organizaciones conforman la muestra y, a su vez, está dividida en un grupo experimental (200 clientes) y un grupo control (200 clientes). Precisamente, para incrementar los niveles de confianza, se determinó de manera aleatoria la clasificación de esta muestra. A través de un sorteo se eligió a los clientes que pertenecen al grupo experimental y a los otros clientes que forman parte del grupo control.

\subsection{Variables de estudio}

Esta investigación tiene dos variables: una independiente y otra dependiente.

\subsubsection{Variable independiente: La organización de sesiones de trabajo como técnica de Relaciones Públicas}

Analizada en función de los resultados obtenidos en el cuestionario de la organización de sesiones de trabajo como técnica de Relaciones Públicas. Para complementar el entendimiento de la variable independiente y sus respectivos indicadores que la conforman, se resume de la siguiente manera:

Figura 2: La organización de sesiones de trabajo como técnica de Relaciones Públicas.

\begin{tabular}{|c|c|}
\hline DIMENSIONES & INDICADORES \\
\hline $\begin{array}{l}\text { Realización de sesiones } \\
\text { de trabajo como técnica } \\
\text { de Relaciones Públicas. }\end{array}$ & $\begin{array}{l}\text { - } \text { Programación de las sesiones de trabajo. } \\
\text { - } \text { Tarjeta de invitación a las sesiones de trabajo. } \\
\text { - Temática de las sesiones de trabajo. } \\
\text { - Calidad del expositor en las sesiones de trabajo. } \\
\text { - Material entregado en las sesiones de trabajo. } \\
\text { - Recepción y registro a los clientes en las sesiones de trabajo. } \\
\text { - Lugar en donde se realizan las sesiones de trabajo. } \\
\text { - Equipamiento técnico en las sesiones de trabajo. } \\
\text { - } \text { Montaje. } \\
\text { - } \text { de trabionamiento y valet parking asignado a los clientes en las sesiones } \\
\text { - } \text { Medimento ofrecido a los clientes en las sesiones de trabajo. } \\
\text { - Cartelería en las sesiones de trabajo. }\end{array}$ \\
\hline $\begin{array}{l}\text { Evaluación general de la } \\
\text { realización de sesiones } \\
\text { de trabajo como técnica } \\
\text { de Relaciones Públicas. }\end{array}$ & Satisfacción general con la realización de las sesiones de trabajo. \\
\hline
\end{tabular}

Fuente: Elaboración propia.

\subsubsection{Variable dependiente: La imagen}

Analizada en función de los resultados obtenidos en la escala de actitudes de imagen de una empresa privada del rubro de tecnologías de la información. A continuación se detallan las dimensiones, los indicadores y los ítems que conforman la variable dependiente: 
Figura 3: Imagen de una empresa privada del rubro de tecnologías de la información.

\begin{tabular}{|c|c|c|}
\hline DIMENSIONES & INDICADORES & ÍTEMS \\
\hline $\begin{array}{l}\text { Elemento } \\
\text { componente } \\
\text { cognitivo de la } \\
\text { imagen-actitud. }\end{array}$ & $\begin{array}{l}\text { - } \text { Productos. } \\
\text { - } \text { Actividades. } \\
\text { - } \text { Conducta. }\end{array}$ & $\begin{array}{l}\text { - } \text { Calidad. } \\
\text { - Precio. } \\
\text { - Plaza. } \\
\text { - Publicidad. } \\
\text { - Promoción de ventas. } \\
\text { - } \text { Utilidad. } \\
\text { - Organización. } \\
\text { - Integridad. }\end{array}$ \\
\hline $\begin{array}{l}\text { Elemento } \\
\text { componente } \\
\text { emocional de la } \\
\text { imagen-actitud. }\end{array}$ & $\begin{array}{l}\text { - } \text { Productos. } \\
\text { - Actividades. } \\
\text { - Conducta. }\end{array}$ & $\begin{array}{l}\text { - Sentimientos en relación con los productos/servicios por la } \\
\text { empresa. } \\
\text { - Sentimientos en relación con las actividades de la empresa. } \\
\text { - Sentimientos en relación con la conducta de la empresa. }\end{array}$ \\
\hline $\begin{array}{l}\text { Elemento } \\
\text { componente } \\
\text { conductual de la } \\
\text { imagen-actitud. }\end{array}$ & $\begin{array}{l}\text { - } \quad \text { Productos. } \\
\text { - Actividades. } \\
\text { - Conducta. }\end{array}$ & $\begin{array}{l}\text { - Decisión de compra en relación con los productos ofrecidos } \\
\text { por la empresa. } \\
\text { - Evaluación del producto ofrecido por la empresa. } \\
\text { - Confirmación de asistencia a las actividades en general que } \\
\text { organiza la empresa. } \\
\text { Asistencia a las actividades en general que organiza la } \\
\text { - Inpresa. } \\
\text { - Aceptación de la conducta de la empresa. }\end{array}$ \\
\hline $\begin{array}{l}\text { Satisfacción en } \\
\text { general que tienen } \\
\text { los clientes de una } \\
\text { empresa. }\end{array}$ & $\begin{array}{l}\text { - } \text { Productos. } \\
\text { - Actividades. } \\
\text { - } \text { Conducta. }\end{array}$ & $\begin{array}{l}\text { - Nivel de satisfacción con los productos y servicios de la } \\
\text { empresa. } \\
\text { - Nivel de satisfacción con las actividades de la empresa. } \\
\text { - Nivel de satisfacción con la conducta de la empresa. }\end{array}$ \\
\hline
\end{tabular}

Fuente: Elaboración propia.

\subsection{Técnicas para la recolección de datos}

Las técnicas de recolección utilizadas fueron las encuestas dirigidas a los 400 clientes de una empresa privada del rubro de tecnologías de la información en Lima Metropolitana 2011-2012.

\subsection{Instrumentos en la recolección de datos}

Se construyeron dos instrumentos de medición: un cuestionario y una escala de actitudes que fueron aplicados a los 400 clientes de una empresa privada del rubro de tecnologías de la información en Lima Metropolitana 2011-2012, durante su participación en una sesión de trabajo como técnica de Relaciones Públicas. Asimismo, los 400 clientes no respondieron los mismos cuestionarios, el grupo experimental (200 clientes) sí respondió a los dos instrumentos de medición y el grupo control solo respondió a la escala de actitudes. El formato empleado buscó ahorrar espacio en el instrumento y facilitar la comprensión del mecanismo de respuesta. 
Figura 4: Instrumentos de medición.

\begin{tabular}{|l|l|}
\hline CUESTIONARIO & ESCALA DE ACTITUDES \\
\hline $\begin{array}{l}\text { Variable independiente } \\
\begin{array}{l}\text { La organización de sesiones de trabajo } \\
\text { como técnica de Relaciones Públicas. }\end{array}\end{array}$ & $\begin{array}{l}\text { Imagen de una empresa privada del rubro } \\
\text { de tecnologías de la información. }\end{array}$ \\
\hline
\end{tabular}

Fuente: Elaboración propia.

\subsubsection{Cuestionario de la organización de sesiones de trabajo como técnica de Relaciones Públicas}

Compuesto por 2 dimensiones, 15 indicadores y 55 ítems. Asimismo, los 55 ítems incluyen preguntas cerradas, de las cuales 13 preguntas son dicotómicas, 36 preguntas con varias opciones de respuesta, 2 preguntas distractoras con la finalidad de hacer menos tedioso el proceso de auto administrado realizado por los clientes; 2 preguntas negativas (son aquellas que niegan el asunto que se interroga) y dos preguntas abiertas relacionadas con el nivel de satisfacción en general con la realización de sesiones de trabajo.

\subsubsection{Escala de actitudes de imagen de una empresa privada del rubro de tecnologías de la información}

Compuesto por 4 dimensiones, 12 indicadores y 25 ítems. En este sentido, la escala de actitudes tiene 25 afirmaciones-ítems, que incluyen ítems con opción a una respuesta, relacionadas con la imagen que tienen los clientes de la empresa. Además, cada ítem se mide con 5 opciones de respuesta (a manera de escala), que van desde totalmente de acuerdo, de acuerdo, ni de acuerdo ni en desacuerdo, en desacuerdo, hasta totalmente en desacuerdo.

\subsection{Análisis y resultados de la muestra piloto}

Luego de elaborar y comprobar la validez y confiabilidad de los instrumentos de medición, se hizo una prueba piloto a fin de aplicar las encuestas a una muestra de 25 clientes (con las mismas características), antes de llevar a cabo la sesión de trabajo para 400 clientes. En este sentido, se utilizó el mismo diseño de investigación a través del estadístico (Alfa de Cronbach), cuyos resultados determinaron que la hipótesis planteada se cumplió. A continuación se explica el procedimiento realizado: 
Figura 5: Muestra piloto de la investigación.

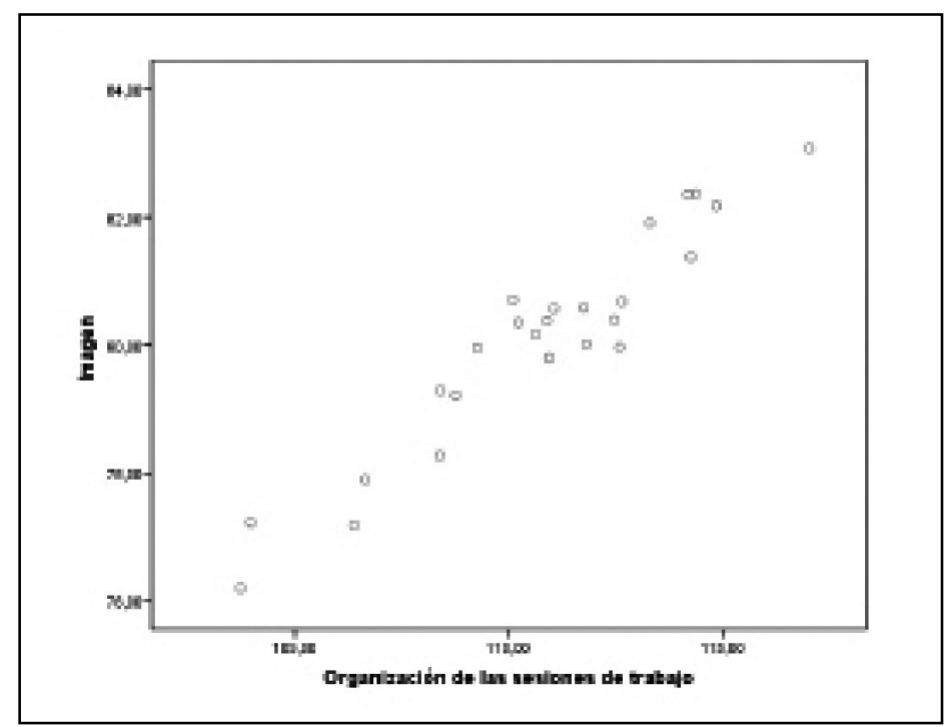

Fuente: Elaboración propia.

En la dispersión (figura 5) se distingue una relación lineal entre las variables a través de un análisis de correlación se comprobó esta impresión gráfica, previamente se realizó un análisis de normalidad:

Figura 6: Resultados del análisis de normalidad en las variables.

\begin{tabular}{|c|c|c|}
\hline & $\begin{array}{c}\text { ORGANIZACIÓN DE SESIONES } \\
\text { DE TRABAJO }\end{array}$ & IMAGEN \\
\hline $\mathbf{Z}_{\mathrm{ks}}$ & 0.513 & 0.771 \\
\hline P valor & $95.5 \%$ & $59.2 \%$ \\
\hline
\end{tabular}

Fuente: Elaboración propia.

Los resultados (figura 6) determinaron que existe normalidad en la organización de las sesiones de trabajo para niveles de significación inferiores al $95.5 \%$, y existe normalidad en la imagen que tienen los clientes de una empresa para niveles de significación inferiores al 59.2\%. Los resultados del análisis de correlación se muestran en la siguiente tabla: 
Figura 7: Resultados del análisis de correlación en las variables.

\begin{tabular}{|c|c|c|c|c|}
\hline $\mathbf{r}$ & $\mathbf{T}$ & $\begin{array}{c}\text { GRADOS DE } \\
\text { LIBERTAD }\end{array}$ & $\begin{array}{c}\text { VALOR CRÍTICO } \\
\text { COLA DERECHA }\end{array}$ & $\begin{array}{c}\text { PROBABILIDAD } \\
\text { ASINTÓTICA }\end{array}$ \\
\hline 0.955 & 15.44 & 23 & 1.71 & 0 \\
\hline
\end{tabular}

Fuente: Encuesta piloto realizada a los clientes (elaboración propia).

Los resultados que aparecen en la figura 7 permiten contrastar los supuestos:

- H0: La organización de las sesiones de trabajo como técnica de Relaciones Públicas no influye en la imagen que tienen los clientes de una empresa privada del rubro de tecnologías de la información en Lima Metropolitana 2011-2012.

- H1: La organización de las sesiones de trabajo como técnica de Relaciones Públicas influye en la imagen que tienen los clientes de una empresa privada del rubro de tecnologías de la información en Lima Metropolitana 2011-2012.

Así, con estos resultados (figura 7) se rechazó la hipótesis nula y se aceptó como verdadera la hipótesis alternativa para cualquier nivel de significación que se fije. Entonces, se confirma con el estadístico de prueba que se valora en 15.44 y está por encima del valor crítico fijado en 1.71 para un nivel de significación del 5\%.

\subsection{Técnicas para el procesamiento y análisis de los datos}

Las técnicas que se usaron para el procesamiento y análisis de la información se realizaron a través del enfoque cuantitativo y del programa de computación con la ayuda de un paquete estadístico (Statistical Package for the Social Sciences SPSS, versión 19). A través de este software, se pudo obtener las pruebas estadísticas para determinar la relación entre las variables y prueba de Chi cuadrado.

\section{Hipótesis de trabajo}

\subsection{Hipótesis general}

La organización de sesiones de trabajo como técnica de Relaciones Públicas influye en la imagen que tienen los clientes de una empresa.

\subsection{Hipótesis específicas}

- La realización de las sesiones de trabajo (como técnica de Relaciones Públicas) influye en el elemento componente cognitivo, emocional y conductual de la 
imagen-actitud que tienen los clientes de una empresa, así como en la satisfacción general que estos pueden experimentar ante una organización.

- La evaluación general de las sesiones de trabajo (como técnica de Relaciones Públicas) influye en el elemento componente cognitivo, emocional y conductual de la imagen-actitud que tienen los clientes de una empresa, así como en la satisfacción general que estos pueden experimentar ante una organización.

\section{Rol profesional del Relacionista Público}

Las Relaciones Públicas conforman una disciplina que desde sus orígenes hasta la actualidad ha evolucionado sin dejar de estudiar al hombre en tanto público, vinculado al ámbito de las organizaciones. A través de los cuatro modelos de Relaciones Públicas ("agente de prensa/publicity", "información pública", "asimétrico bidireccional" y "simétrico bidireccional") de Grunig y Hunt (cf. 2000: 73), se puede observar, comprender y analizar la evolución histórica conceptual, comunicacional e investigativa de las Relaciones Públicas, traduciéndose así el desarrollo de la actividad profesional del relacionista público.

Si bien es cierto que la presencia del relacionista público en algunas organizaciones no es tomada en cuenta en toda su real dimensión (debido a que las áreas o departamentos de comunicación están conformados por otros profesionales especializados en marketing, publicidad, periodismo, entre otros), merece particular importancia que la alta dirección evalúe su incorporación en la estructura formal de la organización, o de lo contrario contratar los servicios de una agencia o consultora de Relaciones Públicas, a fin de contar con un profesional capaz de diagnosticar, direccionar, gestionar y evaluar las relaciones y comunicaciones entre la organización y sus públicos. En ese sentido, Harlow sostiene lo siguiente:

"Las Relaciones Públicas son una función directiva independiente, que permite establecer y mantener líneas de comunicación, comprensión, aceptación y cooperación mutuas entre una organización y sus públicos; implica la resolución de problemas; ayuda a los directivos a estar informados y poder reaccionar ante la opinión pública; define y destaca la responsabilidad de los directivos que deben servir el interés público; ayuda a la dirección a mantenerse al día y a utilizar los cambios de forma efectiva, sirviendo como un sistema de alerta para ayudar a anticipar las tendencias; utiliza la investigación y las técnicas de comunicación éticas como principales herramientas" (ápud Wilcox, Cameron y Xifra, 2006: 7).

Manteniendo el mismo criterio y reafirmando la importancia de la función de las Relaciones Públicas en las organizaciones, la International Public Relations Association (1978) define: 
"La práctica de las Relaciones Públicas es el arte y la ciencia de analizar tendencias, predecir sus consecuencias a los líderes de la organización y poner en práctica programas de acción planificados que servirán tanto al interés de la organización como del público”.

De esta manera, el relacionista público es quien está mejor preparado para desempeñar estas actividades, gracias a su formación académica y experiencia profesional, con el propósito de contribuir a establecer y mantener relaciones duraderas con los públicos, haciendo uso de la comunicación como instrumento para el logro de sus objetivos. En adición a esta afirmación, el Colegio Profesional de Relacionistas Públicos del Perú (2014), explica sobre las actividades del relacionista público, sin embargo para fines de esta investigación, es preciso resaltar que "corresponden a su campo funcional, asimismo, la organización de certámenes y eventos, el ceremonial y el protocolo institucional, la relación con los medios de comunicación, la proyección de prestigio e imagen en general, y la enseñanza de las Relaciones Públicas"7.

Con referencia a la organización de certámenes, acontecimientos especiales y eventos, algunas organizaciones buscan acercarse a sus públicos a través de estas reuniones, pero al tener diferentes clasificaciones, estilos y características, es el relacionista público quien debe evaluar el tipo de evento que más se adecue al cumplimiento de los objetivos de la organización y entendimiento con sus públicos. Xifra (2007:178) señala lo siguiente:

"La organización de eventos ocupa un lugar privilegiado respecto de otras técnicas y especialmente aquellos eventos que tienen una finalidad bidireccional, en la que la organización quiere atraer a sus públicos de su comunidad geográfica para darse a conocer o para informar sobre algún aspecto concreto".

En esta línea, se podría definir un evento como "un acontecimiento que requiere de una planificación previa. Se desarrolla en un momento puntual en el tiempo, con un principio y un final previamente conocido, independientemente de que pueda poseer una periodicidad establecida" (Huaripata, 2013: 46). Justamente, la presente investigación se centra en un tipo de evento, denominado "sesión de trabajo como técnica de Relaciones Públicas", y se demuestra que al organizarlo (de manera planificada por un relacionista público) dicha reunión contribuye a la formación de la imagen que tienen los clientes de una empresa.

\subsection{Sesiones de trabajo como técnica de Relaciones Públicas}

Para comprender las sesiones de trabajo, es importante entender la definición de técnica: "conjunto de procedimientos y recursos de que se sirve una ciencia o un arte" (PalenciaLefler, 2008: 49). Las Relaciones Públicas hacen uso de las técnicas porque a través de

7. El Decreto Supremo No 021-2004-ED aprueba el Estatuto del Colegio Profesional de Relacionistas Públicos del Perú, en el que se detallan las actividades del relacionista público en el capítulo II: "De la Profesión de Relaciones Públicas, campo de acción y funciones". 
estas últimas es posible explicar sus bases conceptuales, procedimientos de planificación, ejecución, seguimiento y evaluación para cada técnica en particular, con la finalidad de lograr sus objetivos y transmitir de manera precisa y oportuna los mensajes a sus públicos de la organización. Xifra (2007: 13) acota lo siguiente:

"Las técnicas definen la manera en que (los procesos a través de los cuales) el profesional de las Relaciones Públicas enfocará el tema, cómo gestionará la transmisión de los mensajes a los públicos objetivo de la estrategia. Es decir, el cómo hacerlo".

En ese sentido, se considera a las sesiones de trabajo como una técnica de las Relaciones Públicas, ya que cumplen con mayor precisión los procedimientos, recursos y las acciones de esta disciplina. Así, dichas sesiones de trabajo (al ser vistas como técnicas) deben ser organizadas por un relacionista público, considerando cada uno de los elementos y recursos que intervienen en su realización. De acuerdo con Palencia-Lefler (2008: 286) las reuniones tratan
"un conjunto de técnicas que responden a la iniciativa de la organización que pretende 'encontrarse' o 'reunirse' con distintos públicos externos y se les obsequia con algún tipo de ágape o comida. En ocasiones la comida será la excusa para reunirse (sesiones de trabajo) mientras que el protagonismo lo tiene una actividad técnica o intelectual".

En adición a lo explicado, las sesiones de trabajo (como técnica de Relaciones Públicas) responden a los objetivos que la empresa (de alguna manera) busca cumplir con sus clientes: presentación de un nuevo proyecto, conmemoración de un acontecimiento o fecha importante, compartir la cultura organizacional, reunir a los clientes para un acto informativo/formativo, comunicar algún mensaje de tarea $^{8}$ o mensaje humano ${ }^{9}$, etc. En cualquiera de las situaciones se logra el entendimiento entre la organización y sus públicos. Noguero (1996: 175) agrega que "este tipo de reuniones grupales o sesiones de trabajo son utilizables, tanto como nexo de públicos identificables por su convocatoria, como de públicos identificados por su asistencia abierta y libre por parte de los interesados". El autor se refiere a las reuniones grupales o sesiones de trabajo como un mismo concepto, en el que los públicos (participantes) responden a ciertas características demográficas, psicográficas, etc., en relación con el objetivo del evento y de la organización.

\footnotetext{
8. Los mensajes de tarea son aquellos que informan a los empleados sobre la manera de realizar sus trabajos. Incluyen actividades como capacitación, orientación, establecimiento de objetivos, resolución de problemas, sugerencia de ideas (Goldhaber, 1994: 128).

9. Los mensajes humanos son aquellos que están dirigidos a los individuos de la organización, considerando principalmente sus actitudes, su satisfacción y su realización (ibidem: 129).
} 
Por ese motivo, es importante mencionar que existen diferentes tipos de sesiones de trabajo. Palencia-Lefler ( $c f$. 2008: 286) las clasifica en: $a$ ) desayuno; b) almuerzo; $c$ ) coctel, refrigerio, tentempié, merienda y piscolabis; y $d$ ) cena. Así, este tipo de ágape o comida es ofrecido a los clientes durante el evento: cada uno tiene características propias y, por lo mismo, responden a distintos objetivos de comunicación que deben ser considerados de manera individual antes de ser llevados a cabo.

El desayuno "habitualmente se diseña como un evento de trabajo, para informar de las últimas novedades a los clientes o realizar una conferencia informativa/formativa ante un pequeño auditorio de públicos selectos, entre otras alternativas" (Palencia-Lefler, 2008: 286). Asimismo, el formato del desayuno ${ }^{10}$ permite que los públicos invitados tengan más posibilidades de asistir al evento al realizarse a primera hora del día, por lo general entre las 8 y 10 de la mañana, y no se cruza con otras actividades.

El almuerzo "es el tipo de sesión de trabajo que presenta más variedad de platos y su elección depende de la cultura gastronómica del país y del tipo de invitados al evento" (Huaripata, 2013: 55). Cuadrado (2011: 248), por su parte, explica que "suele durar dos horas. Durante la comida es normal que se aborden los temas que han de tratarse, pero no será hasta la sobremesa cuando se planteen de manera más profunda o cuando se adopten decisiones". Precisamente, el almuerzo puede realizarse con fines de trabajo como de celebración, en el que se tratan diversos temas, pero siempre están sujetos a un programa, a fin de no perder la naturaleza de la reunión.

Los términos coctel, refrigerio, tentempié, merienda, piscolabis "responden etimológicamente a conceptos diferentes, tienen significados suficientemente parecidos como para presentarse conjuntamente" (Palencia-Lefler, 2008: 288). Tienen la particularidad de que la comida es ligera. Este formato ofrece un contexto distinto a los anteriores (desayuno y almuerzo), porque no necesariamente están sujetos a un protocolo; es decir, el ambiente es relajado, pero siempre mantiene relación con el objetivo de la reunión. Huaripata (2013: 59) recomienda que el relacionista público

"debe ser muy cauto al seleccionar este tipo de formato porque deberá comunicar adecuadamente a sus públicos el objetivo de la reunión. Es muy distinto un refrigerio a un cocktail, a un gerente general no se le puede invitar un refrigerio, porque la empresa daría la imagen que no tiene presupuesto, por ello se deben seleccionar adecuadamente los alimentos".

A diferencia de los otros tipos de sesiones de trabajo, la cena ofrece a los clientes un evento de mayor calidad y "cuenta con un alto nivel de protocolo en la estructuración de dicha reunión y puede conseguir gran ceremoniosidad en su ejecución. Sirve pues a objetivos

10. El desayuno también ofrece variedades como Welcome Coffee (café de bienvenida), Coffee Break (pausa para tomar un café) y desayuno buffet (desayuno con más variedad de alimentos). 
de cultivación y reconocimiento de la organización hacia sus públicos" (Palencia-Lefler, 2008: 289). Como resumen, Cuadrado (2011: 245) explica que

\begin{abstract}
"las comidas de trabajo surgen ante la necesidad de trasladar los asuntos laborales a un marco más distendido y cordial. En ocasiones una negociación que ha quedado en fase de estancamiento por la postura irreconciliable de sus partes puede solucionarse durante una comida precisamente porque el ambiente se relaja y los ánimos se apaciguan".
\end{abstract}

De esta manera, el relacionista público es quien elige y organiza el tipo de sesión de trabajo que mejor permita comunicar los mensajes de la organización a sus públicos, pero, además, siempre debe existir el feedback entre ambas partes, de lo contrario no se conseguirá una comunicación simétrica bidireccional con los referidos públicos.

\title{
5.2. La organización de sesiones de trabajo como técnica de Relaciones Públicas
}

Luego de haber desarrollado las sesiones de trabajo como técnica de Relaciones Públicas, es importante conocer la forma de organizar estas reuniones por el relacionista público, quien considera diversos elementos antes, durante y después del evento, con el propósito de obtener los resultados esperados como, por ejemplo, colmar las expectativas de los públicos de la organización. Chiavenato y Villamizar (1999: 107) definen así a la organización:

"Función administrativa y parte del proceso administrativo (como la planeación, la dirección, la coordinación y el control). En este sentido, organización significa el acto de organizar, estructurar e integrar los recursos y los órganos responsables de la administración, establecer relaciones entre ellos y fijar sus atribuciones respectivas".

En ese sentido, "se entiende a la organización de sesiones de trabajo como la planificación en general de un determinado tipo de evento utilizado como técnica de Relaciones Públicas" (Huaripata, 2013: 62). La organización de sesiones de trabajo no es tarea sencilla, ya que requiere de un tratamiento especial. Por consiguiente, para un mejor desarrollo del proceso de la investigación, esta se ha divido en dos dimensiones: a) realización de las sesiones de trabajo y b) evaluación general de la realización de las sesiones de trabajo.

\subsubsection{Realización de sesiones de trabajo como técnica de Relaciones Públicas}

Se trata de la primera dimensión de la organización de sesiones de trabajo, que se refiere a las funciones administrativas como la planeación, la organización, la dirección y la coordinación que realiza el relacionista público para ejecutar dicha sesión de trabajo. De esta manera, la realización de las sesiones de trabajo implica

"la ejecución de todo lo planificado, preparado y considerado para

llevar a cabo una sesión de trabajo. Para su desarrollo intervienen 
aspectos referentes a la programación de sesiones de trabajo, la convocatoria, la tarjeta de invitación, la temática de la sesión de trabajo, la calidad del expositor, el material entregado, la recepción y registro de los clientes, el lugar en donde se realizan las sesiones de trabajo, el equipamiento técnico, el montaje, el estacionamiento $\mathrm{y}$ valet parking asignado a los clientes, el alimento ofrecido a los clientes, las medidas de seguridad, y la cartelería" (ibídem: 64).

Asimismo, cada uno de estos aspectos (indicadores) se subdividen en otros elementos (ítems) con el propósito de que el relacionista público lleve un mejor control de las actividades a realizar. Así, por ejemplo, la programación de sesiones de trabajo está conformada por: el día, el horario, la puntualidad al iniciar la sesión de trabajo, la puntualidad al finalizar la sesión de trabajo y la duración de la sesión de trabajo. Este aspecto es importante porque con estos datos es que se da inicio a la planeación del evento y se define una serie de acciones tales como la fecha para realizar la convocatoria (con la debida antelación); la preparación y el reparto de las invitaciones (físicas o electrónicas); la definición del tema, que debe ser actual, interesante y útil. De igual modo, se busca a los expositores con mejor aptitud y dominio de tema; se elabora y entrega material a los asistentes al evento (folletos, avisos y folders).

Durante la recepción y registro de los clientes debe existir un trato especial (cordial y natural), el lugar en donde se realice el evento debe ser accesible: "la elección del lugar de celebración es una de las tareas más importantes y complicadas con las que tiene que enfrentarse el organizador de conferencias" (Seeking y Farrer, 1999: 47). También es importante el correcto funcionamiento del equipamiento técnico (iluminación, climatización, equipo de sonido/audiovisual y musicalización). Se debe prever el montaje (ubicación de muebles y equipos) y el otorgamiento del servicio de estacionamiento y valet parking para los clientes.

Otro aspecto que el profesional de las Relaciones Públicas debe tener en cuenta es el alimento ofrecido a los clientes. Este se caracteriza por su calidad, cantidad (suficiente) y presentación, que "suele ser un componente decisivo a la hora de evaluar una comida. Por ello es conveniente la combinación de formas, colores, consistencia y, además, graduar la intensidad de los sabores, comenzando por los suaves y luego aumentar su potencia" (Del Carril y Gill, 2008: 95).

Asimismo, se deben considerar las medidas de seguridad durante el evento: las zonas de evacuación, la vigilancia y la señalética, a fin de garantizar la integridad física de los asistentes. Como último aspecto está la cartelería empleada en las sesiones de trabajo, conformada por la calidad, la cantidad, la colocación y el diseño de los letreros que contienen publicidad tanto del evento como de la empresa. Finalmente, como ya se ha mencionado, la organización y ejecución de las sesiones de trabajo deben estar a cargo del relacionista público y por su equipo de trabajo: solo así se garantizará el éxito de la reunión. 


\title{
5.2.2. Evaluación general de la realización de las sesiones de trabajo como técnica de Relaciones Públicas
}

Viene a ser la segunda dimensión de la organización de sesiones de trabajo y “es el análisis y control que se hace a la sesión de trabajo luego de su realización (planeación, organización, dirección, coordinación)" (Huaripata, 2013: 91). En ese sentido, Chiavenato y Villamizar (1999: 105) explican que el control consiste "en la verificación para comprobar si todas las etapas marchan de conformidad con el plan adaptado, las instrucciones transmitidas y los principios establecidos. Su objetivo es ubicar las debilidades y los errores para rectificarlos y evitar su repetición". Es importante precisar que la evaluación no necesariamente es realizada por la empresa que organiza la sesión de trabajo. Con la finalidad de evitar sesgos en la investigación se considera la opinión de los públicos como

\begin{abstract}
"la valoración que hacen los clientes sobre la realización de la sesión de trabajo a la que han asistido. Esta evaluación permite a la empresa conocer la percepción de los clientes sobre la realización de esta reunión y detecta las valoraciones (positivas o negativas) que se han formado" (Huaripata, 2013: 157).
\end{abstract}

Dicho así, merece toda la atención y esfuerzo del relacionista público realizar correctamente la sesión de trabajo porque finalmente son los clientes quienes evalúan todos los aspectos y elementos dados durante la realización del evento en sí. Por otro lado, la evaluación general de la realización de sesiones de trabajo mide aspectos como la satisfacción en general con la realización de la sesión de trabajo y, a su vez, está conformada por tres elementos: a) nivel de satisfacción en general con la sesión de trabajo; b) reclamos en relación con la sesión de trabajo; y c) sugerencias en relación con la sesión de trabajo.

El primero se refiere al grado de conformidad expresado y demostrado que tienen los clientes en relación con la sesión de trabajo, pero de manera general, porque los clientes no tienen por qué conocer cada uno de los aspectos que sí considera el relacionista público para realizar el evento; por tal razón, aquí la evaluación es de manera general. El segundo elemento hace referencia a la disconformidad por parte del cliente en su participación en el evento. Por último, se aceptan todas las sugerencias (recomendaciones, contribuciones y aportes) de los clientes, con el objetivo de mejorar la organización de futuras reuniones. Lo más importante de la organización de sesiones de trabajo es que los públicos, sobre la base de su participación, se forman una imagen parcial, positiva o negativa y, a la vez, esta percepción influye en la imagen que tienen de la empresa.

\subsection{Imagen}

Otro concepto importante es la imagen entendida como "representación mental de un estereotipo de un objeto, organización, personas o acontecimiento, que los públicos se forman como consecuencia de la interpretación de la información acerca de aquellos" (Capriotti, 1992: 25). Para comprender la presente investigación explicaremos sobre la imagen que tienen los clientes de una organización, llámese empresa, institución pública 
o asociación civil sin fines de lucro. En esta línea de ideas, consideramos que el término "interpretación" se refiere a la valoración que los públicos tienen de una organización; esto no solo se debe a la información recibida, sino también tiene que ver con la relación y experiencia que existe entre ambas partes. Así, estos públicos se pueden formar una imagen positiva o negativa de la empresa.

Al hablar de una organización se suele hacer referencia a los productos y servicios que ofrece, a las actividades que realiza, entre ellas las sesiones de trabajo como técnica de Relaciones Públicas, y a la conducta que muestra ante sus públicos. Es decir, estamos hablando de una imagen general, pero puede darse el caso que algunos clientes solo prefieran consumir los productos y servicios de la empresa, y no estén muy interesados en sus actividades o si la conducta que tiene la organización es coherente con lo que ofrece.

En cualquier situación, es importante que los clientes, al igual que los otros públicos, se formen una imagen general de la empresa y sobre todo que sea positiva. ¿Qué sucede cuando pasa lo contrario?, ¿es posible modificar la imagen que tienen los públicos de una organización? En relación con la interrogante anterior, Carlson (1989: 208 y 391) responde que las Relaciones Públicas "constituyen un esfuerzo organizado para comunicar información y modificar las actitudes y el comportamiento en beneficio de un cliente o de una causa" y que engloba "actividades y políticas de información mediante las que las empresas y otros tipos de organizaciones buscan crear actitudes favorables para ellas mismas y para su trabajo, y contrarrestar actitudes adversas". En este sentido, podemos comprender que sí es posible modificar las actitudes y el comportamiento de los clientes de una organización haciendo uso de las Relaciones Públicas.

\subsection{Imagen-actitud}

La imagen-actitud debe ser entendida como la actitud (predisposición) que se tiene a una determinada cosa, persona, empresa o situación:

"Se llama imagen-actitud, y no sólo imagen, porque la actitud es una tendencia adquirida y duradera a evaluar un determinado suceso, situación o persona y que posteriormente se actuará en base a la evaluación realizada [...] Para evaluar la imagen de una organización es necesario realizar investigaciones de las actitudes de sus públicos reconociendo cuál es el estereotipo que se han formado los públicos luego de recibir información o haber tenido algún tipo de relación con los productos/servicios, actividades y conducta de la empresa" (Huaripata, 2013: 117 y 118).

Relacionando esta línea con el objetivo de la investigación, debemos recordar que si buscamos determinar si la organización de sesiones de trabajo como técnica de Relaciones Públicas influye en la imagen que tienen los clientes de una empresa, es muy importante primero conocer las actitudes y conductas de los públicos, a fin de determinar si efectivamente existe una relación entre ambas variables de estudio. 


\subsubsection{Elementos componentes de la imagen-actitud}

A través de los tres elementos componentes de la imagen-actitud: cognitivo, emocional y conductual, propuestos por Capriotti ( $c f .1992: 25$ y 26), es posible conocer la actitud (predisposición) de los clientes. Esto se debe a que la suma de los elementos componentes es la imagen de la organización. Sin embargo, también es importante conocer la valoración que los clientes tienen de la organización. Por tal razón la investigación incorpora una nueva dimensión llamada "satisfacción en general que tienen los clientes en relación con la empresa”, que permite conocer en toda su amplitud la conducta de dichos clientes.

En tal sentido, para una mejor comprensión y desarrollo de la investigación, se ha clasificado a la imagen en cuatro dimensiones: $a$ ) elemento componente cognitivo, $b$ ) elemento componente emocional, $c$ ) elemento componente conductual y $d$ ) la satisfacción en general de los clientes hacia la referida organización. Asimismo, cada una de estas tiene como indicadores a los productos y servicios, actividades y conducta de la empresa.

\section{a) Elemento componente cognitivo de la imagen-actitud}

Este elemento corresponde a la primera dimensión de la imagen. Tiene como objetivo conocer las creencias, ideas, pensamientos que tienen los clientes sobre los productos, servicios y actividades y de la empresa. Huaripata (2013: 121) explica que el elemento componente cognitivo de la imagen-actitud está conformado por los siguientes elementos (ítems): la calidad, el precio, la plaza, la publicidad, la promoción de ventas, el proceso de compra y la utilidad; un indicador corresponde a las actividades de la empresa, organización; y un indicador corresponde a la conducta de la empresa, la integridad”.

En este sentido, cada uno de estos aspectos y elementos considerados por la autora han sido clasificados de esa manera con el propósito de conocer con mayor precisión la actitud que los clientes tienen frente a dichos elementos. Posteriormente, el relacionista público evalúa los resultados y planifica las acciones comunicacionales con el objetivo de mejorar y mantener la relación armoniosa entre la organización y sus públicos.

Es importante mencionar que los clientes valoran mucho la calidad de los productos que adquieren. Así, Chias y Xifra (2008: 32) sostienen que

"la calidad del producto es quizás el elemento más importante y el más difícil de definir, ya que para el consumidor la percepción de la calidad es muy variable. Por lo tanto, se tiene que distinguir entre la calidad intrínseca del producto y la calidad extrínseca o percibida".

De esta manera, los clientes no solo valoran las características propias de los productos (calidad intrínseca), sino también toman en cuenta sus propias valoraciones (calidad extrínseca). La calidad de los productos y servicios contribuye de alguna manera a conseguir y mantener relaciones duraderas con los públicos. Otro elemento importante es que cuando un producto y servicio es preferido por el público, el factor precio no es determinante para 
concretar la compra, pero sucede lo contrario cuando no existe una relación constante, ya que si el precio del producto se ha incrementado, posiblemente no se realice la compra, y se elija otros que tengan una mejor oferta de ventas. También se debe considerar que el lugar en donde se venden los productos sea accesible para los consumidores.

Por otro lado, se debe considerar la publicidad utilizada para influir en los consumidores, además de ofrecer promoción de ventas que "se orientan a modificar el comportamiento de compra inmediato de los consumidores" (Peter y Olson, 2006: 426). El proceso de compra debe ser eficiente y debe desarrollarse en el tiempo estipulado a los clientes. Y, por último, el producto debe ser útil. Referente a las actividades que realiza la empresa, es importante que el relacionista público pueda establecer los criterios y lineamientos necesarios para llevar a cabo dichas actividades, sin olvidar que cada una de ellas debe ser planificada de manera individual a fin de cumplir los objetivos trazados.

Finalmente, la conducta de la empresa se refiere al comportamiento que tiene con sus clientes. Está conformada por un elemento: integridad, que viene a ser la virtud de la empresa de actuar correctamente y ser coherente entre lo que dice y lo que hace. Además, la empresa debe mostrar respeto y confianza hacia sus públicos, quienes constantemente la evalúan y se forman una imagen general.

\section{b) Elemento componente emocional de la imagen-actitud}

Este elemento corresponde a la segunda dimensión de la imagen y explica acerca de aquellos sentimientos de agrado, desagrado, aceptación, cariño, rechazo, incluso hasta de odio, que los clientes tienen de una organización en función a sus productos, servicios, actividades y conducta. Los sentimientos, de alguna manera, son determinantes en la formación de la imagen que los públicos tienen de una organización, que, como bien se ha dicho, puede ser negativa o positiva.

Huaripata (cf. 2013: 131) clasifica al elemento componente emocional de la imagen-actitud en: a) sentimientos en relación con los productos y servicios, b) sentimientos en relación con las actividades de la empresa, y c) sentimientos en relación con la conducta de la empresa. La autora también menciona que "los sentimientos son el conjunto de emociones percibidas, detectadas e interpretadas por los clientes en relación a los productos/servicios", por lo que también lo hacen con las actividades y conducta de la empresa.

Cada uno de los aspectos mencionados responden al propósito de conocer, con mayor precisión, los sentimientos de los clientes frente a los referidos productos y servicios, actividades y conducta de la empresa. De esta manera, el relacionista público debe evaluar si los sentimientos de los clientes son igual en todos los casos o si ocurre de manera especial con alguno de ellos y, luego de ello, establecer estrategias de comunicación para conservar el vínculo entre la empresa y sus públicos. Es preciso mencionar que cuando una organización actúa de manera íntegra y muestra respeto a sus públicos, además de formarse una imagen positiva, guardan y comparten un sentimiento de confianza, fidelidad, admiración, y hasta de amor, que a través del tiempo se mantendrá. 


\section{c) Elemento componente conductual de la imagen-actitud}

Es la actitud (predisposición) de los clientes para actuar de manera determinada ante los productos, servicios, actividades y conducta de la empresa, y este elemento corresponde a la tercera dimensión de la imagen. Pérez y Solórzano (2000: 98) señalan que

"la imagen es un esquema de conductas y una proyección del yo. Es un perfil de actitudes que reflejará cómo es percibida una empresa, una institución, una entidad, (o un producto, en ciertos casos) y en función de los cuales el público actúa".

Manteniendo la línea de estos autores, los clientes pueden tener una actitud para adquirir los productos y servicios; asistir y participar en las actividades; valorar la conducta de la empresa, pero no necesariamente significa que lo hagan. Esto se debe a que las percepciones del público no se convierten en actuación, que es la acción en sí. Este elemento también está conformado por tres dimensiones que vienen a ser $a$ ) los productos y servicios, $b$ ) las actividades y c) la conducta de la empresa. A su vez, cada uno está conformado por diferentes elementos (ítems) que permiten un mejor desarrollo de la investigación y entendimiento al evaluar la actitud de los clientes en su forma de actuar frente a determinada situación.

Los productos están relacionados con la decisión de compra y la evaluación del producto. Es decir, se debe reconocer que esta etapa es determinante porque es el momento en que el cliente efectúa la compra de un producto y/o servicio, en el que intervienen factores de influencias sociales y personales ( $c f$. Huaripata, 2013: 133). Después de la compra, el cliente evalúa su conformidad o rechazo con dicha adquisición. Dicho así, el profesional de Relaciones Públicas debe coordinar con otras áreas (marketing, logística y producción) para que los productos y servicios cumplan los mejores estándares de calidad, de lo contrario no se concretará la compra.

Del mismo modo, las actividades de la empresa están conformadas por la confirmación de asistencia a las actividades en general y el interés en las actividades que organiza, por lo que el relacionista público debe evaluar por qué algunas veces los clientes suelen confirmar su participación, pero que finalmente no llegan a asistir (aunque también se dan casos en que los clientes no tienen interés en participar). Así, se podrán establecer planes de comunicación a fin de hacer más interesantes las convocatorias a las actividades y buscar los mejores mensajes y canales de comunicación. La conducta de la empresa se representa en la aceptación de la conducta por parte de los clientes: "significa que los clientes comparten y aprueban el comportamiento de la empresa como ser social, vivo, que actúa en relación a su entorno buscando siempre transmitir sus mensajes para mantener una estrecha relación con sus públicos" (ibídem: 142).

\section{d) Satisfacción en general que tienen los clientes de una empresa}

Es importante desarrollar este cuarto y último aspecto de la imagen que se agregó a fin de complementar los tres elementos componentes de la imagen-actitud de Capriotti (cf. 1992, 
25-26) que permiten conocer la actitud de los públicos, mas no la conducta. La satisfacción en general que tienen los clientes de una empresa se configura como "la conformidad expresada y demostrada por los clientes en relación a la empresa, y al hacerlo evalúan a los productos y servicios que ofrece, a las actividades que realiza y a las conductas que muestran ante ellos" (Huaripata, 2013: 142).

De esta manera, no basta con conocer la actitud (predisposición) que los clientes tienen de una determinada situación: también se requiere conocer la conducta de dichos clientes, es decir, conocer la forma en la que actúan y así se puede conocer (sobre la acción en sí) cuál es la imagen que tienen de una empresa (positiva o negativa), por lo que al final el relacionista público puede conocer y determinar si existe una satisfacción en general con la empresa. Para conocer la satisfacción en general que tienen los clientes de la empresa sobre sus productos, servicios, actividades y conducta, es necesario conocer el nivel de satisfacción que estos públicos tienen de la organización (ibidem: 143). Kotler y Keller (2006: 144) explican lo siguiente:

"El nivel de satisfacción del cliente después de la compra depende de los resultados de la oferta en relación con sus expectativas previas. En general, la satisfacción es una sensación de placer o de decepción que resulta de comparar la experiencia del producto (o los resultados) con las expectativas de beneficios previas. Si los resultados son inferiores a las expectativas, el cliente queda insatisfecho. Si los resultados están a la altura de las expectativas, el cliente queda satisfecho. Si los resultados superan las expectativas, el cliente queda muy satisfecho o encantado".

En este sentido, el relacionista público también debe conocer y evaluar qué tan satisfechos se encuentran los clientes con las actividades que organizan y la conducta de la empresa, a través de sugerencias y reclamos por la web, el buzón de sugerencias, vía telefónica, por correo electrónico, cartas o de manera personal. En el caso que no exista un nivel mínimo de satisfacción, este profesional debe evaluar y analizar los resultados y hacer un planeamiento estratégico para mejor la imagen de la organización.

\section{Resultados ${ }^{11}$}

Los resultados de la investigación se han organizado en función de las hipótesis planteadas.

\subsection{Influencia de la organización de sesiones de trabajo como técnica de Relaciones Públicas en la imagen que tienen los clientes de una empresa}

Se utilizó la organización de las sesiones de trabajo como técnica de Relaciones Públicas,

\footnotetext{
11 Mediante diferentes estadísticos (Kolmogorov Smirnov, Kruskal Wallis y el estadístico T) se obtuvieron los resultados. Se trabajó con el paquete estadístico IBM SPSS, versión 19.
} 
como variable independiente y la imagen que tienen los clientes de una empresa, así como variable dependiente, a fin de demostrar que existe influencia entre ambas variables.

Primero se efectuó un análisis exploratorio mediante un diagrama de dispersión para analizar el comportamiento de los datos entre la variable independiente y dependiente. En el siguiente gráfico (figura 8) se indica su respectivo comportamiento:

Figura 8: Organización de sesiones de trabajo y la imagen que tienen los clientes de una empresa.

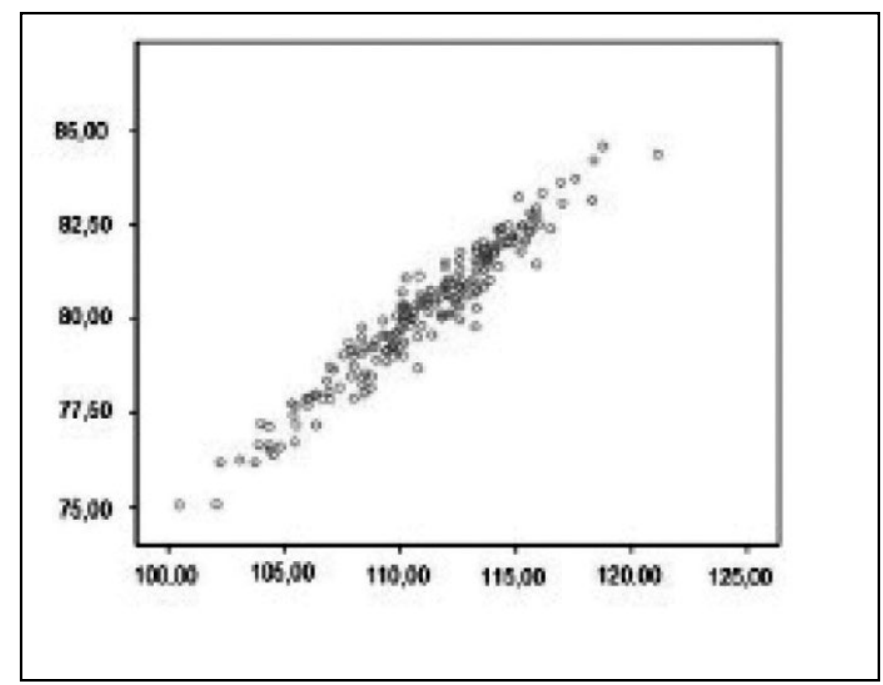

Fuente: Elaboración propia.

La figura 8 sugiere un comportamiento lineal de los datos. Esta evidencia orienta el estudio a un análisis de correlación lineal, que requiere que las variables tengan distribución normal en la población de donde fueron extraídas. Para su demostración se utilizó el estadístico $Z_{\mathrm{ks}}$, de Kolmogorov Smirnov, cuyos resultados se muestran en la siguiente tabla (figura 9):

Figura 9: Test de normalidad de la organización de sesiones de trabajo y la imagen que tienen los clientes.

\begin{tabular}{|c|c|c|}
\hline & $\begin{array}{c}\text { ORGANIZACIÓN DE SESIONES } \\
\text { DE TRABAJO }\end{array}$ & $\begin{array}{c}\text { IMAGEN QUE TIENEN LOS } \\
\text { CLIENTES }\end{array}$ \\
\hline $\mathbf{Z}_{\mathrm{ks}}$ & 0.808 & 0.715 \\
\hline $\begin{array}{c}\text { Probabilidad } \\
\text { asintótica }\end{array}$ & 0.531 & 0.685 \\
\hline
\end{tabular}

Fuente: Elaboración propia. 
Con los resultados (figura 9) se concluyó que la organización de sesiones de trabajo tiene distribución normal en la población para niveles de significación inferiores al 53.1\%. Asimismo, la imagen que tienen los clientes de una empresa privada también tiene una distribución normal en la población para niveles de significación inferiores al $68.5 \%$. Por tanto, se concluyó que se cumple el requisito de normalidad del análisis de correlación.

Se planteó las siguientes hipótesis estadísticas para el análisis de la hipótesis principal:

- H0: La organización de sesiones de trabajo como técnica de Relaciones Públicas no influye en la imagen que tienen los clientes de una empresa.

- H1: La organización de sesiones de trabajo como técnica de Relaciones Públicas influye en la imagen que tienen los clientes de una empresa.

En relación con la variable independiente y dependiente, se utilizó un 5\% de nivel de significación. Con referencia a la aceptación o rechazo de alguna de las hipótesis planteadas, se utilizó el estadístico T que tiene una distribución t de Student con 198 grados de libertad. Los resultados obtenidos se muestran en la siguiente tabla (figura 10):

Figura 10: Resultados de la organización de sesiones de trabajo y la imagen que tienen los clientes de una empresa.

\begin{tabular}{|c|c|c|c|c|}
\hline $\mathbf{r}$ & $\mathbf{T}$ & $\begin{array}{c}\text { GRADOS DE } \\
\text { LIBERTAD }\end{array}$ & $\begin{array}{c}\text { VALOR CRÍTICO } \\
\text { COLA DERECHA }\end{array}$ & $\begin{array}{c}\text { PROBABILIDAD } \\
\text { ASINTÓTICA }\end{array}$ \\
\hline 0.967 & 53.41 & 198 & 1.65 & 0 \\
\hline
\end{tabular}

Fuente: Elaboración propia.

Con estos resultados (figura 10) se rechazó la hipótesis nula para cualquier nivel de significación, debido a que la probabilidad asintótica es cero. Esto se confirma con el valor que toma el estadístico $\mathrm{T}$, cuyo cuantil es 53.41, que es mayor al valor crítico de cola derecha cuyo cuantil es 1.65. Por tanto, el cuantil del estadístico T se ubica en la región de rechazo. Por ende, se acepta como verdadera la hipótesis alternativa que sostiene como supuesto que la organización de sesiones de trabajo, como técnica de Relaciones Públicas, influye en la imagen que tienen los clientes de una empresa para cualquier nivel de significación que se utilice. 


\subsection{Influencia de las dimensiones de la organización de sesiones de trabajo como técnica de Relaciones Públicas en las dimensiones de la imagen que tienen los clientes de una empresa}

En la siguiente tabla (figura 11) se exponen los resultados de las hipótesis específicas:

Figura 11: Resultados de las hipótesis específicas.

\begin{tabular}{|c|c|c|}
\hline $\begin{array}{c}\text { DIMENSIONES DE LAS } \\
\text { VARIABLES }\end{array}$ & $\begin{array}{c}\text { LA REALIZACIÓN DE } \\
\text { SESIONES DE TRABAJO } \\
\text { COMO TÉCNICA DE } \\
\text { RELACIONES PÚBLICAS }\end{array}$ & $\begin{array}{c}\text { LA EVALUACIÓN } \\
\text { GENERAL DE LA } \\
\text { REALIZACIÓN DE } \\
\text { SESIONES DE TRABAJO } \\
\text { COMO TÉCNICA DE } \\
\text { RELACIONES PÚBLICAS }\end{array}$ \\
\hline $\begin{array}{l}\text { Elemento componente cognitivo de la } \\
\text { imagen-actitud. }\end{array}$ & $18.9 \%$ & $91.9 \%$ \\
\hline $\begin{array}{l}\text { Elemento componente emocional de la } \\
\text { imagen-actitud. }\end{array}$ & $20.4 \%$ & $77.9 \%$ \\
\hline $\begin{array}{l}\text { Elemento componente conductual de } \\
\text { la imagen-actitud. }\end{array}$ & $20.3 \%$ & $88.8 \%$ \\
\hline $\begin{array}{l}\text { Satisfacción en general que tienen los } \\
\text { clientes de una empresa. }\end{array}$ & & \\
\hline
\end{tabular}

Fuente: Elaboración propia.

\subsection{Análisis comparativo entre grupos}

Se realizó un análisis comparativo entre el grupo de control y el comportamiento del grupo experimental (definidos en "antes del evento" y "después del evento"). Para ello, se plantearon las siguientes hipótesis estadísticas:

- H0: No existe diferencia significativa entre la imagen que tienen los clientes de la empresa en el grupo de control y en el grupo experimental definido entre el "antes" y el "después" del evento.

- H1: Existe diferencia significativa entre la imagen que tienen los clientes de la empresa en el grupo de control y en el grupo experimental definido entre el "antes" y el "después" del evento.

Con el objetivo de comparar al grupo experimental y al grupo control, se fijó un 5\% de nivel de significación, y para el contraste de la hipótesis planteada se utilizó la prueba estadística basada en el estadístico H de Kruskal Wallis, en la que se utilizó una aproximación Chi cuadrado. Los resultados se muestran en la siguiente tabla (figura 12): 
Figura 12: Resultados del análisis comparativo entre grupos.

\begin{tabular}{|c|c|c|c|c|c|}
\hline $\begin{array}{c}\text { RANGO } \\
\text { CONTROL }\end{array}$ & $\begin{array}{c}\text { RANGO } \\
\text { ANTES }\end{array}$ & $\begin{array}{c}\text { RANGO } \\
\text { DESPUÉS }\end{array}$ & $\begin{array}{c}\text { ESTADÍSTICO } \\
\text { DE CONTRASTE } \\
\text { (CHI CUADRADO) }\end{array}$ & $\begin{array}{c}\text { GRADOS DE } \\
\text { LIBERTAD }\end{array}$ & $\begin{array}{c}\text { PROBABILIDAD } \\
\text { ASINTÓTICA }\end{array}$ \\
\hline 300.5 & 100.5 & 500.5 & 532.447 & 2 & 0 \\
\hline
\end{tabular}

Fuente: Elaboración propia.

Con los resultados (figura 12) se rechazó la hipótesis nula para cualquier nivel de significación que se fije. Así, a un $2.5 \%$, se rechaza la hipótesis nula. Por lo tanto, se acepta la hipótesis alternativa que sostiene como supuesto que existe diferencia significativa entre la imagen que tienen los clientes de la empresa en el grupo de control y en el grupo experimental definido entre el antes y después del evento. Se realizó un gráfico de barras de error (figura 13) para visualizar esta diferencia significativa:

Figura 13: Análisis comparativo entre el grupo de control y el grupo experimental definido entre el antes y el después de la organización de la sesión de trabajo.

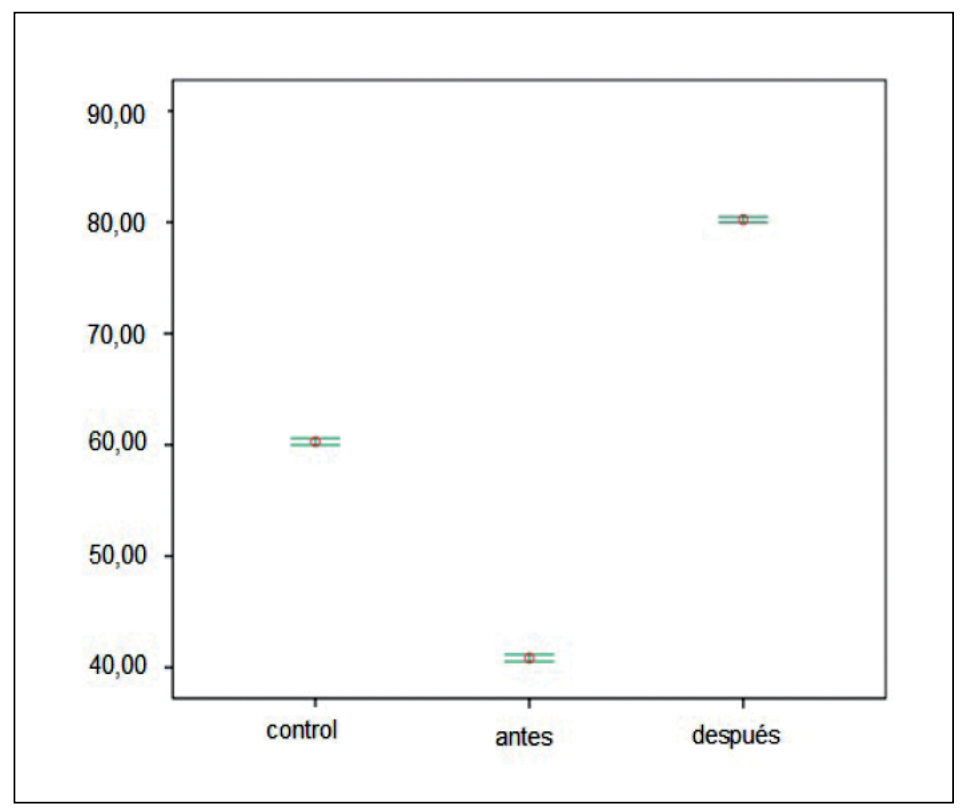

Fuente: Elaboración propia.

En la figura 13, los integrantes del grupo de control se formaron una imagen de la empresa en promedio con una puntuación del 60.3; el grupo experimental tuvo una puntuación de 40.8 sobre la imagen de la empresa y, después de la sesión de trabajo, obtuvo una puntuación de 80.2 . 
Figura 14: Valoración de la imagen que tienen los grupos de la empresa.

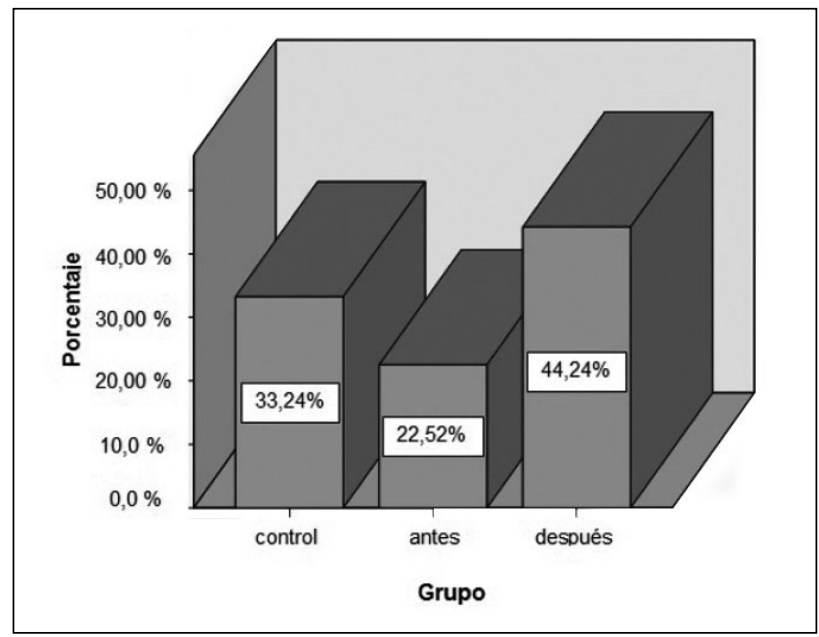

Fuente: Elaboración propia.

La figura 14 permitió determinar que la valoración de los clientes en el grupo de control alcanzó un 33.24\%; no obstante, la variación porcentual en el grupo experimental fue de $11.72 \%$. Esta variación fortalece las actividades de las sesiones de trabajo debido a que este incremento explica que se trabajó con un grupo que asignaba una valoración relativamente baja a la imagen de la empresa; sin embargo, después del evento esta imagen se vio incrementada desde un $22.52 \%$ hasta un $44.24 \%$.

\section{Conclusiones}

Las sesiones de trabajo, como técnica de Relaciones Públicas, pueden ser de mucha utilidad para las organizaciones porque les permite acercarse y reunirse con sus clientes a los cuales se les ofrece un ágape, además de comunicarles algo referente a sus productos, servicios, actividades y conducta. Sin embargo, para garantizar el éxito y satisfacción de los públicos en relación con los eventos, es necesario que sean organizados por un relacionista público y no por cualquier integrante de la organización.

La presente investigación demostró que la organización de las sesiones de trabajo como técnica de Relaciones Públicas influye en la imagen que tienen los clientes de una empresa. En este sentido, de acuerdo con los resultados hallados, se afirma que existe un nivel de correlación del $96.7 \%$ (figura 11) entre ambas variables. Esto demostraría que cuando las sesiones de trabajo son planificadas y organizadas de manera correcta por las empresas son de agrado de sus clientes, quienes se forman una imagen positiva de la empresa. Sin embargo, sucedería todo lo contrario cuando estas reuniones no son planificadas, ya que los públicos sienten que no son valorados y respetados por la empresa. Entonces, a pesar de que los clientes puedan tener una buena relación con la organización, esto ocasionaría que se formen una imagen negativa. 
En este sentido, la imagen es una sumatoria de imágenes parciales y temporales. Es posible modificar las actitudes de los públicos sobre la base de la conducta que muestren, es decir, conociendo cuál es la imagen que tienen de la empresa. Es importante mencionar que si la imagen es positiva, como en este caso, se debe trabajar también los otros aspectos que la conforman con la finalidad de mantenerla, ya que las sesiones de trabajo constituyen solo uno de los aspectos que influyen en la imagen total de la organización y no son determinantes en la formación de la misma.

Considerándose las dimensiones de la variable independiente y dependiente, se demostró que existe un nivel de correlación del $18.9 \%$ entre la realización de sesiones de trabajo (como técnica de Relaciones Públicas) y el elemento componente cognitivo de la imagenactitud que tienen los clientes de una empresa. Entonces, esta correlación se debería a que los clientes no conocen o no necesariamente deberían de conocer cómo es que se realizan las sesiones de trabajo y cuáles son los criterios tomados en cuenta por el relacionista público. Esto demostraría que los clientes solo consideran a la empresa tal como es, sin relacionarla con la sesión de trabajo a la que han asistido. No obstante, el que sepan o no cómo se planifica y realiza la sesión de trabajo no impide que se compruebe la hipótesis general.

Del mismo modo, entre la realización de sesiones de trabajo (como técnica de Relaciones Públicas) y el elemento componente emocional de la imagen-actitud, existe un nivel de correlación del 20.4\%; se podría pensar que para los clientes no es importante cómo se realizan las sesiones de trabajo, en comparación con los sentimientos que tienen sobre la empresa. Esto se demuestra con el resultado obtenido.

Asimismo, se comprobó que existe un nivel de correlación del 20.3\% entre la realización de sesiones de trabajo (como técnica de Relaciones Públicas) y el elemento componente conductual de la imagen-actitud. En tal sentido, se determina que para los clientes tampoco es relevante cómo se realizan las sesiones de trabajo en relación con la conducta de la empresa. Esto no implica que no evalúen el comportamiento final de la empresa. Los clientes tienen una imagen general de la empresa (que puede ser positiva o negativa) y a su vez existen factores como las sesiones de trabajo, que pueden favorecer a que esta imagen general se mantenga o por el contrario se vea disminuida. De tal manera que los públicos se forman una imagen parcial (en relación con su participación al evento) que se complementa a la imagen general que tienen de la empresa. La razón es que las sesiones son una de las tantas técnicas de Relaciones Públicas o uno de los diversos aspectos que conforman la imagen. Dicho así, tal sería la razón por la que existe influencia entre las variables.

La realización de sesiones de trabajo (como técnica de Relaciones Públicas) tienen un nivel de correlación del $20.2 \%$ con la satisfacción en general que tienen los clientes de una empresa. Esto demostraría, una vez más, que no es necesario que los clientes conozcan aspectos sobre la realización de las sesiones de trabajo (llevadas a cabo por las empresas) para valorar la satisfacción en general que puedan tener con la misma. Por otro lado, cuando analizamos la segunda dimensión de la variable independiente con las dimensiones de la variable dependiente, observamos que el nivel de correlación es más alto. La evaluación general de la realización de sesiones de trabajo (como técnica de Relaciones Públicas) tiene 
un nivel de correlación del 91.9\% con el elemento componente cognitivo de la imagenactitud. Esto demostraría que los clientes valoran si la realización de la sesión de trabajo cumplió con sus expectativas.

Lo mismo sucede con la evaluación general de la realización de sesiones de trabajo (como técnica de Relaciones Públicas) porque tiene un nivel de correlación del $77.9 \%$ con el elemento componente emocional de la imagen-actitud. En tal sentido, los sentimientos se volverían más fuertes y estrechos entre la empresa y sus clientes luego de que estos hayan asistido a las reuniones de trabajo y las hayan considerado agradables. De igual manera, la evaluación general de la realización de sesiones de trabajo tiene un nivel de correlación del $88.8 \%$ en el elemento componente conductual de la imagen-actitud que tienen los clientes de una empresa. Esto significaría que el comportamiento que refleja la empresa en sus clientes es importante y es el resultado de la aceptación que los públicos han tenido luego de haber participado y aprobado las sesiones de trabajo como uno de los aspectos que pasan a formar parte de la imagen que se tiene de la organización.

Finalmente, existe un nivel de correlación del $82.7 \%$ entre la evaluación general de la realización de sesiones de trabajo (como técnica de Relaciones Públicas) y la satisfacción en general que tienen los clientes de una empresa (dimensión creada). Este criterio es muy importante para la investigación, porque demostraría que la valoración de los clientes en relación con la realización de sesiones de trabajo permite que ellos tengan una satisfacción en general de la empresa y, sobre todo, porque determinaría cuál es la imagen que se forman los clientes como resultado de su participación en dicha reunión. Sin embargo, es preciso mencionar que de una sesión de trabajo no va a depender únicamente la satisfacción general que se tenga de una empresa.

\section{Fuentes consultadas}

Capriotti, P. (1992). La imagen de la empresa. Estrategia para una comunicación integrada. Barcelona: Concejo Superior de Relaciones Públicas de España.

Carlson, R. (1989). "Relaciones Públicas”. En AA. VV. International Encyclopedia of Communication, vol. 3. Nueva York: Oxford University Press.

Chias, J. y Xifra, J. (2008). Las Relaciones Públicas y el Márqueting. Barcelona: UOC.

Chiavenato, I. y Villamizar, G. (1999). Introducción a la teoría general de la administración. Bogotá: McGraw-Hill.

Colegio de Relacionista Públicos del Perú (2014). "Estatuto del Colegio Profesional de Relacionistas Públicos del Perú (Decreto Supremo N 021-2004-ED)”. Extraída el 6/ VIII/2014 desde http://www.colegioprpperu.org/leyes.htm

Cuadrado, C. (2011). Protocolo y comunicación en la empresa y los negocios. Barcelona: FC Editorial. 
Del Carril, A. y Gill, E. (2008). Cómo organizar eventos exitosos y fiestas inolvidables. Buenos Aires: Aguilar.

Goldhaber, G. (1994). Comunicación organizacional. México D. F.: Diana.

Grunig, J. y Hunt. T. (2000). Dirección de Relaciones Públicas. Barcelona: Gestión.

Harlow, R (1976). "Building a Public Relations Definitions”. Public Relations Review. Vol. 2, núm. 4 .

Hernández, R.; Fernández, C. y Baptista, P. (2010). Metodología de la investigación. México D. F.: McGraw-Hill.

Huaripata, C. (2013). La organización de sesiones de trabajo como técnica de Relaciones Públicas y su influencia en la imagen que tienen los clientes de una empresa privada del rubro de tecnologías de la información en Lima Metropolitana 2011-2012 [tesis de maestría]. Lima: Universidad de San Martín de Porres, Facultad de Ciencias de la Comunicación.

International Public Relations Association (1978, agosto 12). "Declaración de México". Extraída el 11/VIII/2014 desde http://www.unica.edu.do/acuerdomexico.htm

Kotler, P. y Keller, K. (2006). Dirección de marketing. México D. F.: Pearson Educación. Noguero, A. (1996). Programación y técnicas de Relaciones Públicas. Barcelona: EUB.

Palencia-Lefler, M. (2008). 90 Técnicas de Relaciones Públicas. Barcelona: Bresca Profit.

Pérez, R. y Solórzano, E. (1999). Relaciones Públicas Superiores una nueva pedagogía. Lima: USMP.

Peter, P. y Olson, J. (2006). Comportamiento del consumidor y estrategias de marketing. México D. F.: McGraw-Hill.

Seeking, D. y Farrer, J. (1999). Cómo organizar eficazmente conferencias y reuniones. Madrid: FC Editorial.

Wilcox, D.; Cameron, G. y Xifra, J. (2006). Relaciones públicas. Estrategias y tácticas. Madrid: Pearson Educación.

Xifra, J (2007). Técnicas de las Relaciones Públicas. Barcelona: UOC. 